\title{
Experimental hydrodynamic analysis of trimaran-pentamaran with variation transom non-transom on mainhull and sidehull
}

\author{
Yanuar $^{1, *}$, Wiwin Sulistyawati ${ }^{1}$, M Ammar Mahardika ${ }^{1}$, and A Azwin Alfarizsy ${ }^{1}$ \\ ${ }^{1}$ Department of Mechanical Engineering, Universitas Indonesia, Depok 16424, Indonesia
}

\begin{abstract}
One of the most essential aspects of ship is its resistance. There much have been done researches to analyze the reduction of resistance in order to get a good performance; yet the multihull is still one of interesting researches to get the rightest configuration, as to produce minimum resistance. This research is experimental study to obtain the lowest resistance with configuration consisting of stagger, clearance and trim of pentamaran. The pentamaran are performing as a trimaran formation by using Wigley hull with combinations transom on main hull and non-transom on side hulls. Its purpose is also to determine the destructive effects caused by wave interference. The research test conducted on stagger (a ratio of distance of stern main hull to stern side hull to main hull length)-positioning variations of 0.35 and 0.4 . As for clearance (a ration of distance centerline of main hull to centerline of side hull to main hull width)-positioning variations, they exceed $1.05 ; 1.20 ; 1.35$; and 1.50 . The trim variations researched are $0^{\circ} ; 0.5^{\circ}$; and $1.0^{\circ}$. The result of this study was presented by tables and graphs of resistance components of side hull on stagger-clearance and trim condition.
\end{abstract}

\section{Introduction}

The multihull offers the potential for relatively low resistance at high speeds, large deck and volume, also better stability performance than monohull. More researches will be needed to determine the performance of multi-hull ship [1]. Experimental is very important for designs with good hydrodynamics, both of performance and safety. Experimental for multi hull ships was first performed by [2] on a catamaran to obtain optimal hull with minimum resistance, and also by [3] - [7]. Next [8] had analyzed with towing test for Wave Cancellation Multihull (WCM) on Trimaran. Then, [9] as well as [10] optimizing the configuration on Trimaran. And [11] using thin ship theory to determines optimum configuration of multihull to obtain the minimum wave resistance. [12] used computational numerical formulations approach based on theoretical methods of Michell and experimental in determining resistance and motion of catamaran, trimaran, quadrimaran and pentamaran using Wigley hull form on several configuration variations.

Many factors influence on ship's durability. The relative position of sidehull to mainhull is one of the factors that are sensitive to multihull problems. [13] The relative resistance advantages can be associated with different stagger positions of the sidehulls does depend on the relative of speeds. By varying the shape of hull ship and sidehull location to mainhull allow in minimizing the amplitude and energy causing disturbance to the resistance. So that small change in position and modification of the shape of the individual hull can alter the resulting wave system. Therefore, the reduction from wave effect will be possible with proper placement resulting in lower wave resistance.

An objective of this research was to provide a performance base of trimaran-pentamaran comparison between main hull with transom and no transom. Which the side hulls no transom were selected as outrigger.

\section{Test models}

The experiment test was tested in calm water, in accordance to International Towing Tank Conference (ITTC) 1978 for ship resistance components.

\subsection{Hull details}

The research is to study the best position of stagger, clearance and trim configuration of trimaran-pentamaran based on calm water tests on two different models tested. As well as proper configuration in producing destructive effects of wave interference. The model of trimaranpentamaran hulls had been built in fiber reinforced plastic (FRP). Its parameters were given in Table 1. and the design shown in Fig. 1-2. Which displacement of each side hull is about $9 \%$ and the length is $28 \%$ of main hull of displacement and length. The models used Wigley hull that have five hulls consists of a main hull with variation transom on centerline and four outriggers non-transom arranged aside.

\footnotetext{
Corresponding author: yanuar@eng.ui.ac.id
} 

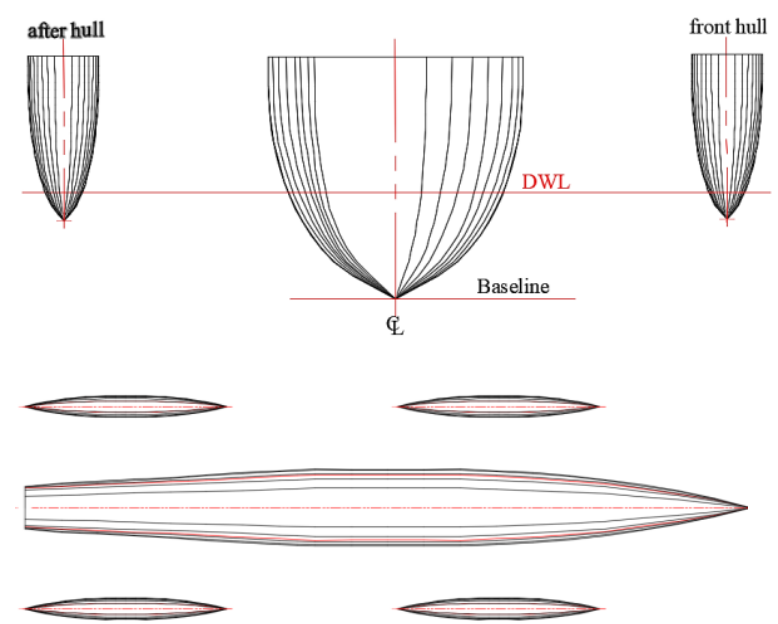

Fig.1. Pentamaran model with transom mainhull (PT)

Table 1. Model parameters

\begin{tabular}{|l|c|c|c|}
\hline \multicolumn{1}{|c|}{ Parameter } & $\begin{array}{c}\text { Mainhull } \\
\text { with transom }\end{array}$ & $\begin{array}{c}\text { Mainhull } \\
\text { no transom }\end{array}$ & Sidehull \\
\hline Length (LOA) $\mathrm{m}$ & 1.800 & 1.800 & 0.500 \\
\hline Breadth $(\mathrm{B}) \mathrm{m}$ & 0.180 & 0.180 & 0.050 \\
\hline Height $(\mathrm{H}) \mathrm{m}$ & 0.170 & 0.170 & 0.116 \\
\hline Draft $(\mathrm{T}) \mathrm{m}$ & 0.080 & 0.080 & 0.030 \\
\hline Block coeff. $(\mathrm{cb})$ & 0.500 & 0.457 & 0.420 \\
\hline Displ. $(\Delta) \mathrm{kg}$ & 11.460 & 10.480 & 0.213 \\
\hline Wetted surf. $\mathrm{m}^{2}$ & 0.381 & 0.368 & 0.033 \\
\hline
\end{tabular}

\subsection{Configuration setting}

The configuration for experiment consist of 16 models test with two variations on stagger and four on clearance. The configurations of test models have been reported in Table 2, which the models name as PT (pentamaran with transom) and PW (pentamaran Wigley). The tests on speed range corresponds to Fn between 0.4 and 0.7 .

This study is for investigation the best position of stagger, clearance, and influence of stern with transom or non-transom also effect of trim angle on $0^{0} ; 0,5^{0}$; $1,0^{\circ}$. It was known that the trim was affected by the side-hull position especially when the closer sidehull to the mainhull.

Table 2. Model names and configurations

\begin{tabular}{|c|c|c|}
\hline Model & Stagger & Clearance \\
\hline $\mathrm{PT} / \mathrm{PW} A$ & $0.35 \mathrm{~L}$ & $1.05 \mathrm{~B}$ \\
\hline $\mathrm{PT} / \mathrm{PW} \mathrm{B}$ & $0.35 \mathrm{~L}$ & $1.20 \mathrm{~B}$ \\
\hline $\mathrm{PT} / \mathrm{PW} \mathrm{C}$ & $0.35 \mathrm{~L}$ & $1.35 \mathrm{~B}$ \\
\hline $\mathrm{PT} / \mathrm{PW} \mathrm{D}$ & $0.35 \mathrm{~L}$ & $1.50 \mathrm{~B}$ \\
\hline $\mathrm{PT} / \mathrm{PW} \mathrm{E}$ & $0.40 \mathrm{~L}$ & $1.05 \mathrm{~B}$ \\
\hline $\mathrm{PT} / \mathrm{PW} \mathrm{F}$ & $0.40 \mathrm{~L}$ & $1.20 \mathrm{~B}$ \\
\hline $\mathrm{PT} / \mathrm{PW} \mathrm{G}$ & $0.40 \mathrm{~L}$ & $1.35 \mathrm{~B}$ \\
\hline $\mathrm{PT} / \mathrm{PW} \mathrm{H}$ & $0.40 \mathrm{~L}$ & $1.50 \mathrm{~B}$ \\
\hline
\end{tabular}

\subsection{Setting-up of tests}

"Corresponding author: yanuar@eng.ui.ac.id

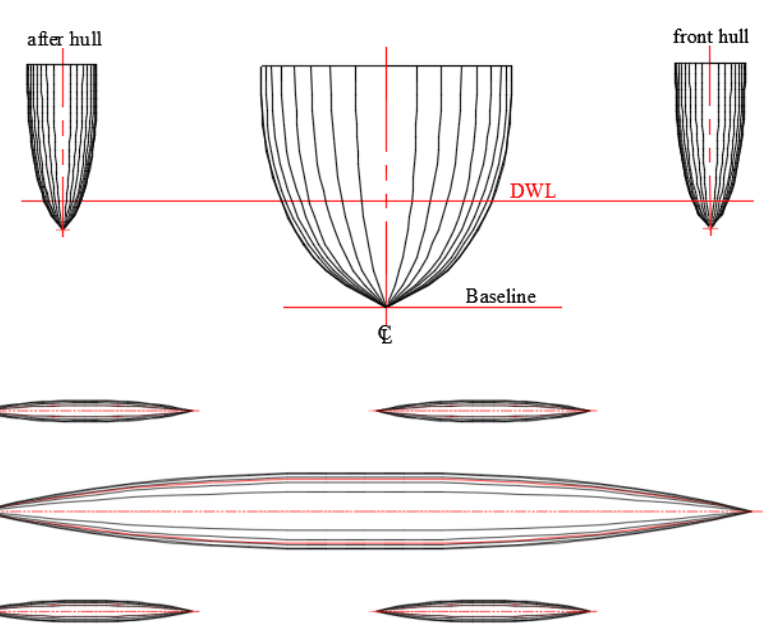

Fig.2. Pentamaran model with Wigley mainhull (PW)

The test was constructed in water tank of Universitas Indonesia that the dimensions are $50 \mathrm{~m} \times 10 \mathrm{~m} \times 2 \mathrm{~m}$ in length, width and depth, respectively. Instrumentations include a dynamometer for resistance measurement, an electric set of DAQ, voltage regulator, electric motor, speed timer and load cell were connected to a set computer where LabView software recorded all the data and made time-averaged measurements of the data. The resistance dynamometer measured on horizontal tensile strength with a tolerance of not more than $0.2 \%$ or 0.05 $\mathrm{N}$ of the maximum capacity of the dynamometer measurements whichever is greater.

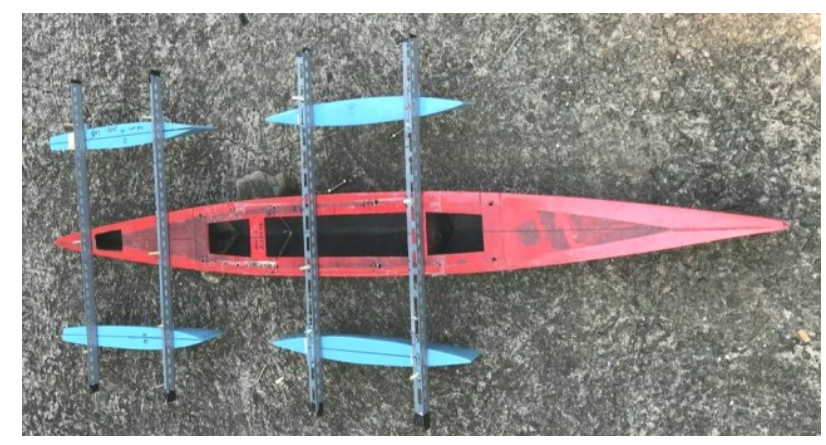

Fig.3. Setting-up experiment model

\section{Resistance calculation}

The total resistance of a hull consists of two main components: frictional, and residuary resistance. The following equation for total resistance is

$$
R_{T}=R_{r}+R_{F}
$$

where $R_{T}$ is the total resistance, $R_{F}$ is the frictional resistance and $R_{r}$ is the residuary resistance. The frictional resistance is caused by the viscous drag of water as the ship move, that causes an increasing boundary layer to the stern of the ship where separation occurs. 
The frictional resistance coefficient using the International Towing Tank Conference of 1957 (ITTC '57) correlation line:

$$
\begin{gathered}
R_{F}=1 / 2 \rho V^{2} S C_{F} \\
C_{F}=0.075 /(\log \operatorname{Re}-2)^{2}
\end{gathered}
$$

Then the total residuary resistance can be calculated using:

$$
R_{r}=R_{T}-R_{F}
$$

The total resistance can also as a summation of wave resistance $\left(\mathrm{R}_{\mathrm{W}}\right)$, and viscous resistance $\left(\mathrm{R}_{\mathrm{V}}\right)$.

$$
\begin{aligned}
& R_{T}=R_{W}+R_{V} \\
& R_{V}=(1+k) R_{F}
\end{aligned}
$$

where $1+\mathrm{k}$ is a form factor that can be obtained experimentally by running tests at low speeds where viscous effects dominate. And about total resistance coefficient $\left(\mathrm{C}_{\mathrm{T}}\right)$ and wave coefficient $\left(\mathrm{C}_{\mathrm{W}}\right)$ can be write

$$
\begin{aligned}
& C_{T}=R_{T} / 1 / 2 \rho V^{2} S \\
& C_{W}=R_{W} / 1 / 2 \rho V^{2} S
\end{aligned}
$$

To analyst a multihull, the resistance of all hulls as a ship configuration from the sum of the resistances when towed individually. Eq. (9) was used to calculate interference resistance:

$$
\Delta R_{T}=R_{\text {Tpenta }}-\left(R_{\text {Tmain }}+4 R_{\text {Tside }}\right)
$$

as a percentage

$$
\% R_{T}=\frac{R_{\text {Tpenta }}-\left(R_{\text {Tmain }}+4 R_{\text {Tside }}\right)}{R_{\text {Tpenta }}}
$$

where $\Delta R_{T}$ is the interference resistance, $R_{T}$ penta is the total resistance as a pentamaran, $\mathrm{R}_{\mathrm{T}}$ main is resistance of mainhull, and $R_{T}$ side is resistance of side hull as individually. Advantageous interference is indicated by negative value of interference [14] that the resistance of as a pentamaran is less than the summed of individual hulls resistances.

This research was also investigated the trim effect on resistance. Trim was measured with respect to influence of the side-hull position even if its position closer to the main hull. To calculate for trim was using the equation of [15].

$$
\text { Trim }=-\left(\Delta Z_{\text {bow }}-\Delta Z_{\text {stern }}\right) 2 g / V^{2}
$$

where $g$ is gravity in $\mathrm{m} / \mathrm{s}^{2}, \mathrm{~V}$ is the velocity in $\mathrm{m} / \mathrm{s}$, $\Delta \mathrm{Zb}_{\text {ow }}$ is variation in free model of bow draft (m), $\Delta$ Zstern is stern draft $(\mathrm{m})$.

\section{Analysis of test results}

Results from all the tests on PT (pentamaran with transom) model include the interference are presented in Fig. $4-7$.

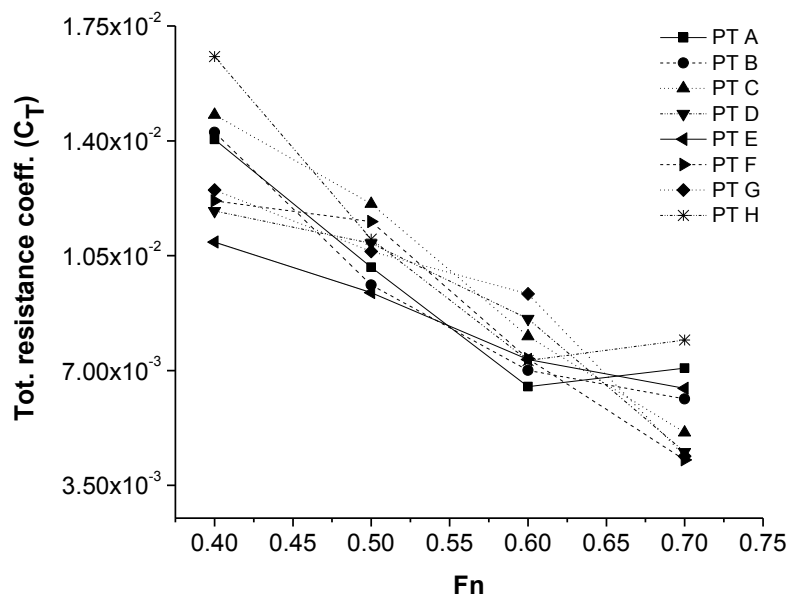

Fig.4. Total resistance coefficients $C_{T}$ of all configurations of model PT

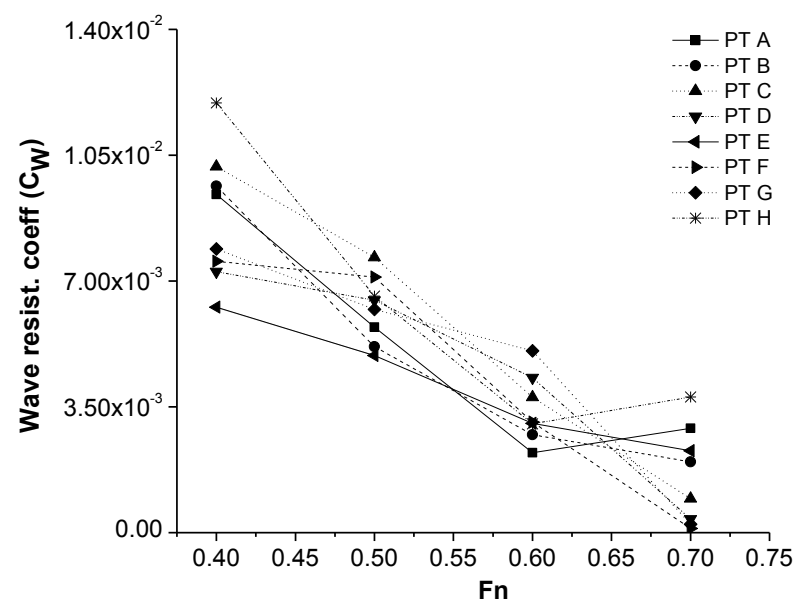

Fig.5. The wave coefficients $C_{W}$ of all configurations of model PT

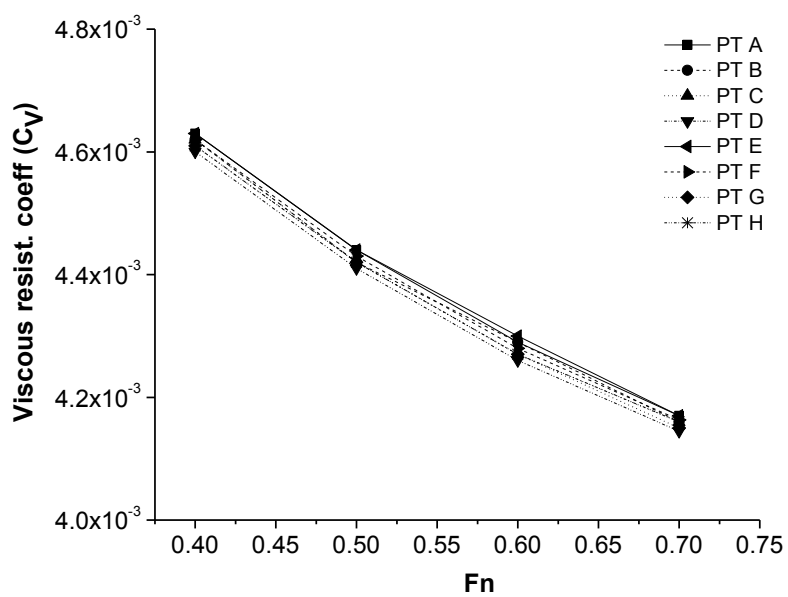

Fig.6. The viscous coefficients $\mathrm{C}_{\mathrm{V}}$ of all configurations of model PT 
The best configuration with the lowest total resistance coefficient at Fn 0.7 is model PT F, stagger $0.4 \mathrm{~L}$ and clearance 1.2B that show in Fig. 4, although at range Fn 0.5 - 0.6 has a high value. Calculation to wave coefficient, $\mathrm{Cw}$ (Fig. 5) give similar trend results with the coefficient of total resistance $\mathrm{C}_{\mathrm{T}}$, and model PT $\mathrm{F}$ still the best model with minimum wave. For viscous results in Fig 6 show that model PT D (stagger 0.35L and clearance $1.5 \mathrm{~B}$ ) generate the lowest viscous than others. But basically, the economic aspect of a ship is determined from the factor of total resistance its produced.

About interference in Fig 7 the lowest results at Fn 0.7 , is generated by model PT F, although for Fn 0.4-0.5 the results give significant differences (high IF). Even at Fn 0.6 that model PT A shows the lowest IF. That's indicated that model PT F is a beneficial model at high speed, i.e. its total resistance was lower than the sum of the resistances of outriggers tested individually.

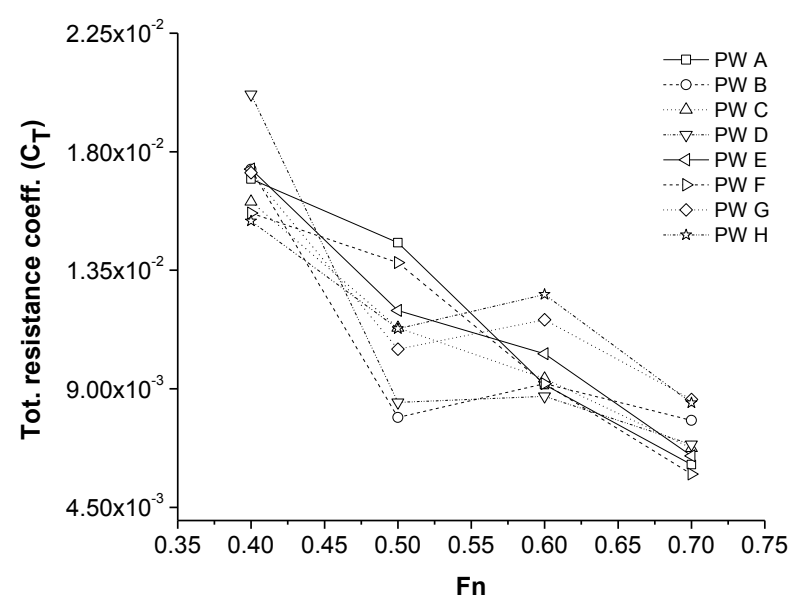

Fig.8. Total resistance coefficients $\mathrm{C}_{\mathrm{T}}$ of model PW

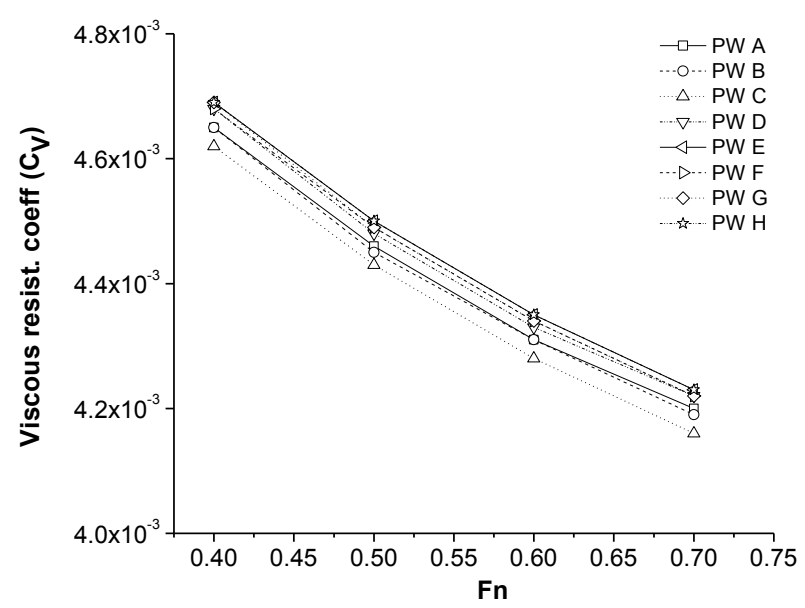

Fig.10. The viscous coefficients $\mathrm{C}_{\mathrm{V}}$ of model PW

The tests result on model PW (pentamaran Wigley) are shown in Fig. 8 - 11. Figure 6 shows that great stagger tend to give minimum results on total resistance coefficient at high speeds. It is also clear from the overall test results in both model PT and PW that position of staggers is more influential to the total resistance coefficient rather than clearance. In Fig. 8

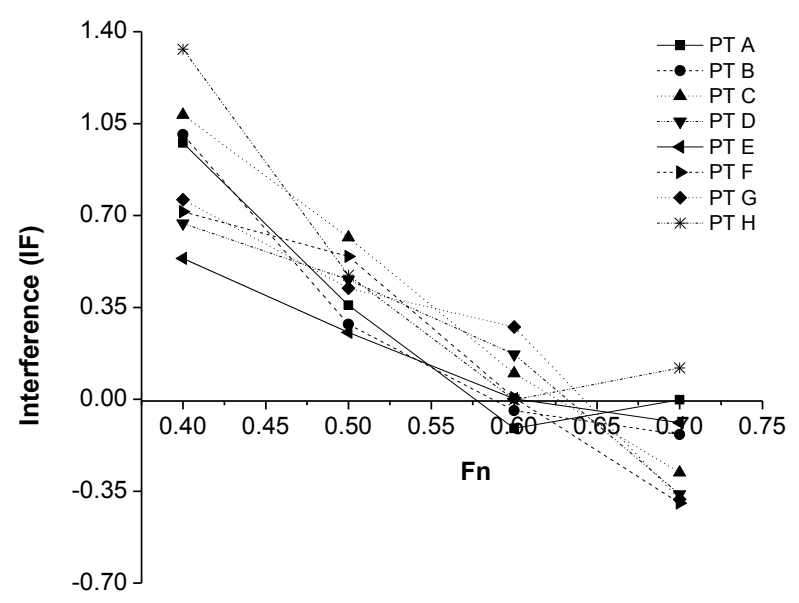

Fig.7. IF results of pentamaran all configurations of model PT

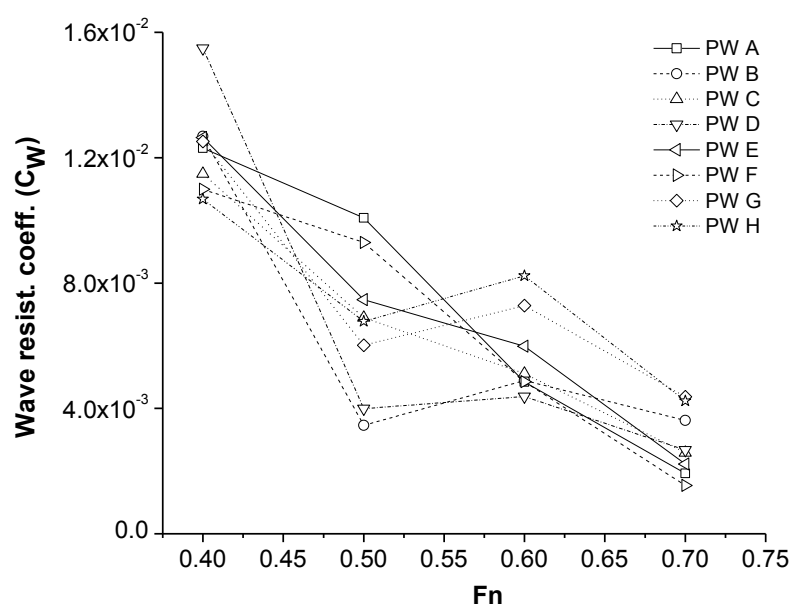

Fig.9. The wave coefficients $\mathrm{C}_{\mathrm{W}}$ of model PW

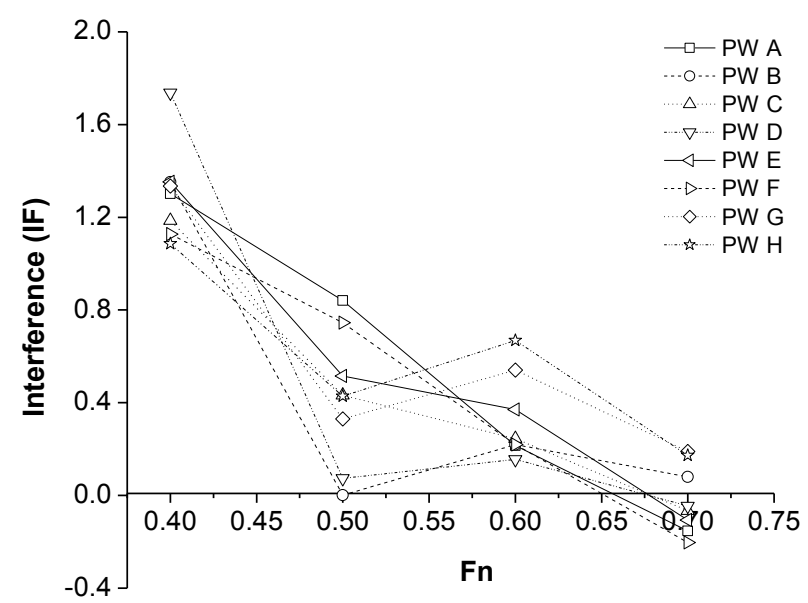

Fig.11. IF results of pentamaran all configurations of model PW

show model PW F (stagger $0.4 \mathrm{~L}$ and clearance 1.2B) obtain the lowest both of total resistance coefficient and wave coefficient (Fig. 9), even also the lowest interference (Fig. 11). However viscous results are shown in Fig 10, model PW C (stagger $0.35 \mathrm{~L}$ and clearance $1.35 \mathrm{~B}$ ) generate the lowest viscous on high speed. 


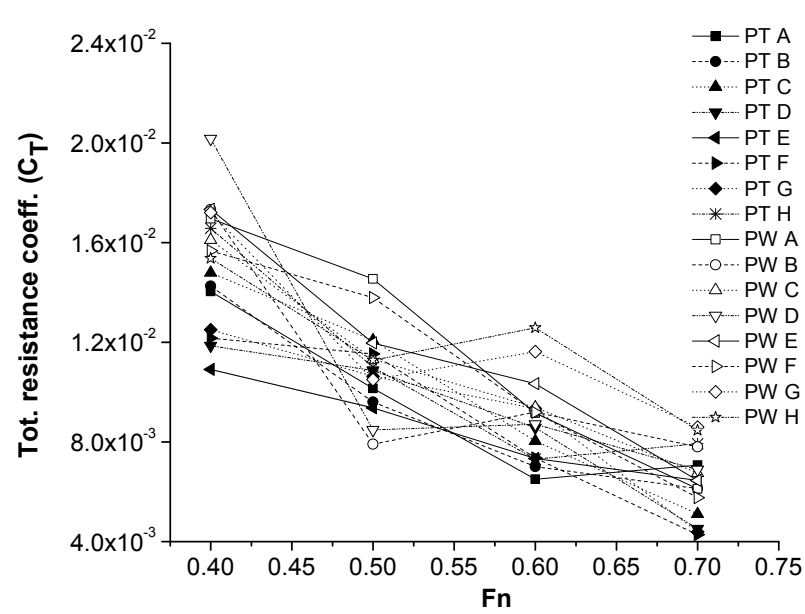

Fig.12. Comparison of $\mathrm{C}_{\mathrm{T}}$ among different models

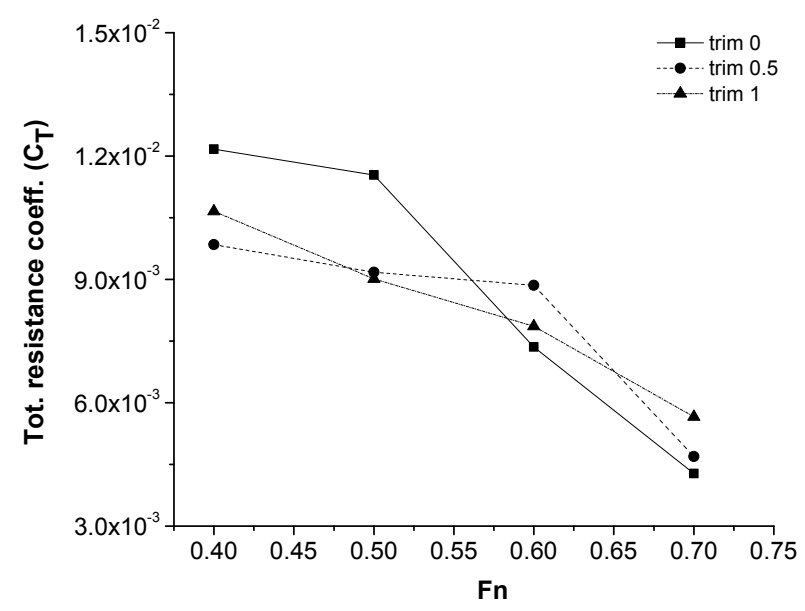

Fig.14. Trim results of all configurations of PT model

[16] A transom stern influential to reduce the occurrence of wave and spray behind the transom and returning flows towards the stern, thereby reducing total ship resistance. This is consistent with the comparison result of PT and PW models in Figures 12 and 13, generally visible of PT model (pentamaran with transom) generate more smaller resistance and wave than PW model (pentamaran Wigley). The results show that the PT F model has the least total resistance and wave value compared to the overall model at Fn 0.7.

It has been noted from the model test with the lowest resistance on both configuration models, then performed with trim test at angle of $0^{\circ} ; 0.5^{\circ}$; and $1.0^{\circ}$ are presented in Figures 14 and 15. The both models PT and PW show the resistance tends to decrease, although at Fn 0.6 the trend of angle trim 0.5 increase and then subsequently down. The best results of model PT are obtained at a fixed draught whereas model PW shows the best results at trim angle of 0.5 .

\section{Conclusions}

This study presents experimental on trimaranpentamaran models on variations mainhull with transom and non-transom. Investigations were performed on the effect of stagger and clearance to the total resistance,

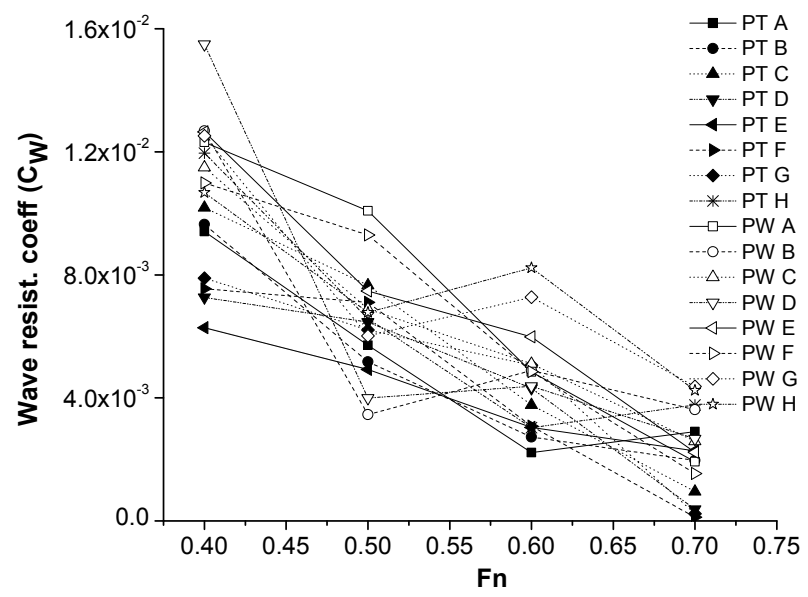

Fig.13. Comparison of $\mathrm{C}_{\mathrm{W}}$ among different models

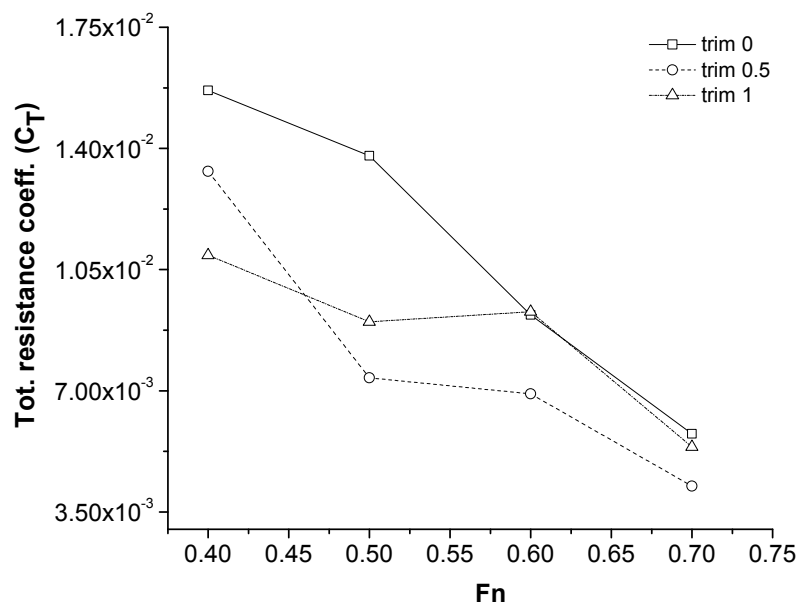

Fig.15. Trim results of all configurations of PW model

wave resistance, viscous, resistance interference factors between hulls and conducted with trim to the best formation. The magnitude reduction of resistance on the trimaran-pentamaran are mainly provided by position of staggers than clearance. Generally model PT (pentamaran with transom) is superior than $\mathrm{PW}$ (pentamaran non-transom/ Wigley) that obtained at stagger $0.4 \mathrm{~L}$ and clearance 1.2B. Significant of interference effects also occur in pentamaran with mainhull transom was shown by more negative interference. At the trim condition tends to reducing resistance at high speed, especially at the trim angle of 0.5 .

Further work should be regarded to tested criteria and method to a be able to investigate on the hulls form and outriggers. And this search can be conducted with fast computational to obtain an optimal stagger and clearance.

This work has been financially supported by by PITTA Grant 2018 funded by DRPM Universitas Indonesia with no. 2562/UN2.R3.1/HKP.05.00/2018. The authors wish to appreciation for the valuable support from pentamaran team of Department of Mechanical Engineering of Universitas Indonesia.

\footnotetext{
Corresponding author: yanuar@eng.ui.ac.id
} 


\section{References}

1. Begovic, E, et al. Pentamaran hull for medium size fast ferries. Hydrodynamics VI (Eds L. Cheng and K. Yeow):23-28 (2004 ).

2. Hsiung, $\mathrm{CC}$, and $\mathrm{H} \mathrm{Xu}$. Determining optimal forms of a catamaran for minimum resistance by the mathematical programming method. Schiffstechnilc, Vol. 35, No. 1, 3-18 (1988).

3. Yanuar, Gunawan, $M$ A Talahatu, Ragil $T$ Indrawati, and A Jamaluddin. Resistance analysis of unsymmetrical trimaran model with outboard sidehulls configuration, J. of Marine Science and Appl. 12, Issue 3, 293-297 (2013).

4. Yanuar, Gunawan, Kurniawan T. Waskito, and A. Jamaluddin. Experimental Study Resistances of Asymmetrical PentamaranModel with Separation and Staggered Hull Variation of InnerSide-hulls, Int. J. of Fluid Mech. Research (2015).

5. Yanuar, Gunawan, A. Muhyi A. Jamaluddin. Ship resistance of quadramaran with various hull position configurations. J. of Marine Science and Appl. 15. Issue 1. 28-32 (2016)

6. Yanuar, Ibadurrahman, Kurniawan T. Waskito, S. Karim and M. Ichsan. Interference resistance of pentamaran ship model with asymmetric outrigger configurations, J. of Marine Sci. and Appl. 16. Issue 1. 42-47 (2017)

7. Yanuar, Ibadurrahman, M.H Faiz and M.H. Adib. Experimental Analysis of Diamond Pentamaran Model with Symmetric and Asymmetric Hull Combinations, J. of Eng. and Applied Sci. 12 (13): 3434-3440 (2017)

8. Wilson, MB, CC Hsu, and DS Jenkins. Experiments and predictions of the resistance characteristics of a wave cancellation multihull ship concept. 23rd American Towing Tank Conf, pp. 103-112 (1993)..

9. Suzuki, Kazuo, and Mitsuhisa Ikehata. Fundamental study on optimum position of outriggers of trimaran from view point of wave making resistance. FAST93, pp. 1219-1230 (1993).

10. Andrews, D., Zhang, J.W. Considerations in the Design of a Trimaran Frigate. Proc of Int symposium of high speed cessel and transport and defence, London, UK (1995).

11. Tuck, EO, DC Scullen, and L Lazauskas. Sea wave pattern evaluation: Part 1 report: Primary code and test results (surface vessels), Department of Applied Mathematics, The University of Adelaide. http://www.scullen.com.au (1999).

12. Peng, Hongxuan. Numerical computation of multihull ship resistance and motion, Dalhousie University Halifax (2001)

13. Doctors, L.J. and Scrace, R.J. The Optimisation of Trimaran Sidehull Position for Minimum Resistance. FAST03, Ischia, Italy (2003)

14. Yeung, R.W., Wan, H. Multi-hull configuration design: a framework for powering minimization. In: Proceedings of the ASME 2007 26th International Conference on Offshore Mechanics and Arctic Engineering (OMAE2007). 4. 833-842 (2007)

15. Kim, Y.H., Jenkins, D. Trim and Sinkage Effects on Wave Resistance with Series 60; $c b=0.60$. Technical report. David W. Taylor Naval Ship Research and Development Center, Bethesda, Maryland (1981)

16. Doctors, L.J. Resistance prediction for transom-stern vessels. Proceedings of Fourth International Conference on Fast Sea Transportation, FAST'97, Sydney, (1997). 